\title{
LAND ART'DA YENI YÖNELIMLER: ECO ART
}

\section{Doç. Berna Okan*}

Özet: Endüstri devrimi sonrasında bozulan doğal-kırsal ortamlara biçimsel katkılarda bulunma eğilimi, iyileştirici, dikkat çekici, çözüm bulmaya yöneliktir. Bu çevresel katkılarda sanatçı doğàya bir nesne gibi değil yaşayan bir canlıymış gibi yaklaşarak diyalog kurar. Burada amaç, doğayı değiştirme çabalarından çok sade, basit, doğal düzenlemelerle fikrin önemini vurgulamaktı. 1960'lı yıllardan beri heykele ilişkin temel kaygılar ve beklentilerin değişmesiyle resim ve heykel yapımında alternatif teknik ve malzemeler kullanılmıştır. Bronzun yerini çer çöp ve doğal malzemeler almıştır.

Bir sanat yapıtı her şeyden önce tasarlanmış olan şeydir. Kendiliğinden estetikleşmiş bir nesne yoktur. Bir taş bir yolun üzerinde durduğu sürece genellikle bir sanat yapıtı değildir ama izlenmek üzere müzede sergilendiğinde bir sanat yapıtı haline gelebilir. Müzeye konduğunda sahip olduğu bazı özellikleri öne çıkarılmış olur. Varlığının farkına varılmayan obje, sanat yoluyla varlık kazanır. Bu şekilde sanatçının müdahaleleri ile anlamlanan çevresel çabalar, insanın Evren’in tahribine karşı aldığı önlemleri de aynı zamanda bir simgesidir.

Anahtar Kelimeler: Doğa, Yeryüzü, Toprak, Çevre, Sanat

\footnotetext{
*Kültür ve Turizm Bakanlığı Güzel Sanatlar Genel Müdürlüğü Hipodrom/Ankara, kaya_okan@yahoo.com, ORCID: 0000-0001-2345-6789
} 


\title{
LAND ART AND NEW ORIENTATION: ECO ART
}

\author{
Assoc. Prof. Berna Okan*
}

\begin{abstract}
The tendency to make formal contributions to the natural environments that deteriorated after the Industrial Revolution is developing, curative and solution-oriented. With these environmental contributions, artists consider nature a living creature, not a thing, and communicate with it accordingly. The aim here is to emphasize the importance of simple and natural arrangements rather than the efforts to change the nature. Since the 1960s, with the change of basic concerns and expectations about sculpture, alternative techniques and materials have been used in painting and sculpture. Instead of bronze, artists have worked with natural materials and trash. On top of everything, artwork is a designed thing. Artwork is not being aesthetic by itself. For instance, a rock on the road is not an art but if a rock is in the museum, it turns into an artwork with its colour and texture. These artistic efforts make the nature meaningful. A plain and hardly recognized object has won value with art. These artistic efforts make environment meaningful, which at the same time is a symbol of precautions taken against the damage on the nature.
\end{abstract}

Keywords: Nature, Earth, Soil, Environment, Art

*Ministry of Tourism and Culture, Administration of Fine Arts, Hipodrom/Ankara, kaya_okan@yahoo.com, 0RCID: 0000-0001-2345-6789 


\section{GíRiș}

Sanat nesnesi dediğimiz şey özerk bir nesne olarak Modernizm’e özgüdür. Ancak 1970’li yıllardan bu yana heykel ve resim artık ne geleneksel ne de modernist anlamıla tanımlayabileceğimiz bir üretim çeşitliliği içindedir. Heykele ilişkin temel kaygılar ve beklentiler de değişmiştir. 'İnsanlar çoğunlukla bazı sanat eserlerini takdir etmezler, çünkü sanatın bir güzellik olduğuna inanırlar ve zihinlerinde bu güzelliği betimleyen bir ön yargı bulundururlar. Oysa bence güzellik doğayı ortaya çıkarmaktır (Gelburd, 2009, 32 ). 1960 kabul edilmiş önermeleri sorgulama eğilimlerinin bir devamı olarak görülür, resim ve heykel de alternatif teknik ve malzemeler kullanılmıştır (Gelburd,2009,35). 1969'da Kosuth 'Kavramsal Sanat', teriminin netleştirilmesi üzerinde durmuştur. Duchamp sanatın odak noktasının biçim olmaktan çıkıp anlam sorunu olduğu ve estetiği sanattan ayırmak gerektiğini vurgulamıştır (Gelburd,2009,47). 1975 öncesi her eğilim kendi başına ayrı varlık göstermişse de 1980’lerin sanatçlları bu dönemi bir bütün olarak algılama eğilimindedirler. Bu dönemde sanatçllar; Sanat nesnesinin alınan-satılan bir nesne olmaması fikrini yerleştirmek, algılama sınırlarını zorlamak, sanat kavramını estetikten ayırmak, galeri - müze sınırlarını aşmak, izleyici de yaratım sürecine katmak gibi çabalar içerisindedirler. 1980'lere gelindiğinde sanatçılar, sanatın artık elle yapılma sınırlılığından kurtulduğunu fabrikada da yapılabileceğini gösterirken kompozisyon ve tasarım gibi biçimsel kaygıların yerini süreç ve anlam almıştır. Çalışmaları bu süreç’te fotoğraflamak, filme almak onların kalıcılığını sağlayan yöntemler arasında yer almıştır.

Rosalind Krauss, 'Genişleyen Mekânda Heykel' isimli makalesinde; 'Geçen on yıl boyunca oldukça şaşırtıcı şeyler heykel olarak adlandırılmaya başlandı: Sonlarında TV monitörleri ile dar koridorlar, ülke gezintilerini belgeleyen büyük fotoğraflar; sıradan odalarda garip açılarla yerleştirilen aynalar, çöl zeminine kazılan geçici çizgiler' şeklinde, 1980 ve sonrasında gündeme oturan Postmodernist tavir içinse belirli bir alanla ilişkili uygulamaların heykel olarak tanımlanamaz diyerek ifade eder (Krauss,1983,1).

Yeni İngiliz sanatçıları arasında gerçek nesnelerle kentsel ikonografik düzenlemeler yapan, Sonrasinda ise buluntu nesneler kullanan Tony Cragg, ruhsal algılamalarla kavranan nesneler üreten Anish Kapoor tanıdık olanlarıdır( Antmen, 2008, 289-290). 'Modernliğin getirdiği kopukluktan önce, bu ölçüde akıl karıştırıcı olmayan sanat yapitlarına insanlar daha kolay yaklaşabiliyordu' (Collins, 2007, 100- 107).

19.yüzyılın sonundan başlayarak, öncelikle sanat yapıtı ile güzellik arasındaki bağı koparmayı amaçlayan karşı çıkış’ın başladığını görebiliyoruz. Gerçeklik çirkin ya da korkunç ise, onun olduğu gibi gösterilmesi, sanat yapıtınınsa yanıltıcı bir zevk vermek yerine, bizi başkaldırmaya ya da iğrenmeye teşvik etmesi gerekir (Lenoir, 2003, 204).

\section{DOĞA VE DEĞișen SANAT}

Bir sanat yapıtı her şeyden önce tasarlanmış olan şeydir. Kendiliğinden estetikleşmiş nesne yoktur. Bugün birçok heykelci eserlerinde, ağaç köklerine, kaya parçalarına veya arazide yağmurun bozduğu, denizde suların aşındırdığı taşlara benzeyen kaba ve işlenmemiş görüntüler bırakmayı ya da taşları hiç değiştirmeden yığmakla yetindikleri görülmektedir. Dolayısıyla 'Bir nesne, belirli anlarda sanat yapıtı olabilir, buna karşılık başka anlarda olmayabilir (Goodman,1992, 199). Doğrusunu söylemek gerekirse, bir nesne belirli biçimde simge olarak işlev gördüğü için ve simge olarak işlev gördügü süre içinde bir sanat yapıtı olabilir. Bir taş bir yolun üzerinde durduğu sürece genellikle bir 
sanat yapıtı değildir ama izlenmek üzere müzede sergilendiğinde bir sanat yapıtı haline gelebilir (Goodman,1992,200). Yolun üzerinde genel olarak hiçbir simgesel işlevi yerine getirmez. Müzeye konduğunda, sahip olduğu bazı özellikleri öne çıkarılmış olur. Örneğin rengi, dokusu gibi. Bir çukurun kazılması normalde ilgimizi çekmeye bilir. Ancak bir yapıt olarak belirlenmesi ona bakış açımızı değiştirir. Örneğin bir Rembrant tablosu, kırılmış bir camın üzerine takılsaydı ya da bir şeyden korunmak amacıyla kullanılsaydı, sanat yapıtı olmaktan çıkardı'. (Goodman, 1992, 204).

Bu durum doğada da böyledir. Birbirine karışmış ot parçaları, rüzgârın büktügü karışık çalılıklar, derin çatlaklarla dolu topraklar, parçalayan ve tahrip eden doğayı alt üst olmuş bir toprağın hüzün verici düzensizliğini telkin eder.

Uygarlıktan kaçmanın birer örneği olan bu Land Art çalışmaları, çevresel düzenlemeler ve Eco Art detayları büyütür ve mercekle bakarak derin bir incelemeye girer. $\mathrm{Bu}$ tavır biçimcilik ve estetiği, sanata dair kabul edilmiş doğruları sorgulayan bir yöntemdir (Lenoir, 2003, 139).

Oldenburg'un Central Park'da bir çukur açması ne kadar sanattır? Bunlar sanat yapıtı ise etrafımızda gördüğümüz tüm ve taş-toprak-çukur sanat yapıtı mıdır? Evet, sanatçının davranışı yapıtın önüne geçtiği sürece bunlar birer sanattır (Lenoir, 2003,140).

Bütünüyle sıradan nesnelerin sanat nesnesi olmasını başka türlü nasıl açılamalı? Bir şeyi sanat yapıtı olarak görmek, gözün fark edemediği bir şeylere sahip olmayı gerektirir (Lenoir, 2003, 150). 'Sanat ile Doğa arasındaki fark, yapış ile genelde davranış ya da ortaya koyuş arasındaki fark gibidir; sanat ürünü ya da sonucu da yapıt (opus) olarak, doğanın ürününden sonuç olarak farklıdır. Hukukta, yalnızca özgür olarak üretime, yani aklı eylemlerin temeline oturtmuş özgür birinin gerçekleştirdiği üretime sanat adının verilmesi gerekir. Çünkü arıların ürettiği peteği sanat yapıtı olarak tanımlamaktan hoşlansak bile, bunu yine de peteği sanatla kıyasladığımız için yaparız; arıların ortaya koyduğu işi kendilerine özgü hiçbir akılcı düşünceye dayandırmaksızın yaptıklarını düşündüğümüz anda, bunun onların doğasından kaynaklanan (içgüdüsel) bir ürün olduğunu ve bu ürünün bir sanat yapıtı olarak yalnızca onları yaratana mal edilebileceğini kabul ederiz'(Lenoir, 2003, 95).

Günümüzde 'Eco Art' adına 'Environmental Art' adına yapılan tüm düzenlemeler ile önemsenmeyene, göz ardı edilene dikkat çekilir. Kusurlar büyütülür ve adeta mercekle bakılarak derin bir incelemeye tabii tutulur. Moore 'İnsanlar çoğunlukla bazı sanat eserlerini takdir etmezler, çünkü sanatın bir güzellik olduğuna inanırlar ve zihinlerinde bu güzelliği betimleyen bir ön yargı bulundururlar. Oysa bence güzellik doğayı ortaya çıarmaktır ve doğanın her zaman takdire değer yanları olmayabilir' diyerek ifade eder (Gelburd, 2009, 67).

Daha önceki koşullarda varlığının farkına varılmayan bu nesnelere varlık kazandırılır. Özellikle çöp ve atık malzemelere Sanatçıların müdahaleleri ile anlamlanan çevresel çabalar, insanın evren’in tahribine karşı aldığ önlemlerin de bir simgesidir. Bu yolla aynı zamanda harap olmuş, terk edilmiş, endüstri, trafik, sanayi ile bozulmuş yerler sanatçıların müdahalesi ile yenilenmektedir. Bazen alanın kendisi hiçbir müdahale olmadan öylece kullanılır. $\mathrm{Bu}$ sanatçılar için entropi-enerjinin giderek azalması ve dünyadaki sistemlerin giderek düzensiz ve dağınık hale gelmeleri en önemli sorunsaldır. Bu sanatçıların kaygıları estetik bir biçim yaratmaktan daha çok çevresel sorunlara dikkati çekmek ve çözüm önerileri getirmek ve doğa’yı iyileştirme amacıdır. 'Şeyler' nesnellik öncesi aşamaya aittir: kendilerine hiçbir kullanış amacı saptanmadığ varlıklarını sürdürmektedirler. Oysa sanat 
yapitının ortaya koyduğu olay da budur. Sanat yapıtı, tersine, teknik bir nesnede malzemeden başka bir şey olmayan ve kullandığı süre içinde yok olan şeye özel bir değer kazandırır ve onun, yer aldığg çerçeve içinde kendisine özel bir konum kazandırır. Hiçbir tasarımın içinde yer almayan, dolayısıyla da olağan koşullarda varlığının farkına varılmayan şeye bir varlık kazandırır (Heiddegger, 2003, 44).

Doğanın bir başka biçimde keşfi ya da doğanın bizzat kendisinin zaman içindeki gelişimi ve değişimini konu alan toprak, yeryüzü, doğa ve çevre ile ilgili olan uygulamalar 1968'den bu yana sit, süreç ve çevrebilim odaklı olarak çeşitlendiğini söyleyebiliriz.

\section{DOĞA ÜZERINDE ÇALIȘAN SAN- ATÇILARDAN ÖRNEKLER}

1960 ve 1970 'li yıllarda sanat, Heizer ve arkadaşları tarafından galerilerin dışına taşınmaya başlamıştır. 'Land Art' adı verilen bu yönelimin öncüleri Heizer, Robert Smithson, Robert Morris, Beuys, Dennis, Oppenheim ve Walter De Maria'dır. Genellikle performansa dayalı ve geçici olma özelliği taşıyan 'Land Art' çalışmalarında materyal genellikle kayalar, taşlar, kum, ağaç dalları ve topraktır. Bu çalışmalar, genellikle doğada yapılır ve orada bırakılır. Böylece doğanın yıkıcı etkilerine maruz kalır. Doğa içinde, denizde, dağ tepelerinde, çölde çalışan sanatçllardan, Heizer ve diğer sanatçıların açık alanlarda yaptığı işler 60 'ların ve 70 'lerin sanat politiğine, eco ruhuna ve en önemlisi nesneleri ticari bir mal gibi gören anlayışa karşı koymayı da yansitmaktadır (Antmen, 2008, 25).

Carl Andre’nin doğa ile giriştiği denemeleri arasında Coloradoda bir ormana dizdiği tahta parçaları ve taş parçalarından bir yığın meydana getirmiştir. Dan Fleming, ağaçlara metrelerce bir dizi halinde resimler asar. Bu resimlerin her biri öncekinden büyüktür. Richard Long ise 'Ağaçlarda Heykel' dediği kompozisyonunda ağaç dallarına astı̆̆ Robert Morris, özellikle taş ocakları, endüstrinin terk ettiği harap olmuş araziler, kent çöplüklerini yeniden canlandırmaya çalışmıştır. Sanatçı, toprak, yeryüzü, doğa birlikteliğini 'Ekolojik Sanat' ile sürdürmeye devam etmiş̧ir. Mel Chin, 'canlandırma alanına' diktiği bitkilerle toprağın asidini temizlemiştir. Heather Mc Gill, tarla kuşlarını geri çağırarak, kaybolmuş bazı nebatları tekrar canlandırmaya çalışmıştır. Patricia Johanson Amazon ve Nijer nehirlerinin temizlenmesi için yapitlar üretmiştir. Johanson, yarattığı ekolojik çevrelere 'Habitat Bahçe' adını verir. Yaptığı birçok uygulamasında insan, su, böcek, kuş, hayvan gibi birçok canlıyı diyalog kuracak şekilde yakınlaştıran biçimler kurmuştur. Andy Goldsworthy, acımasız kent yaşantısına karşı eleştiri getiren, insani duyarlılığı ön plana çıkarmaya çalışan bir sanatçıdır. Sanayi toplumunun oluşturduğu kentler özellikle çevre kirlenmesi sorunlarıyla mücadele etmiştir. Goldsworthy, doğa kaynaklı materyallerle insanlara şaşırtıcı görünümler sunmaya çalışmıştır. Günümüzdeki sanat anlayışına göre, 'Yapıtın üzerinde zorunlu olarak çalışma yapılmış bir şey olması gerekmez; sanat yapıtı her şeyden önce tasarlanmış bir şeydir' (Genette, 1992, 59).

$\mathrm{Bu}$ yaklaşım sanatsal olarak nitelendirilen tüm olaylara dikkat çekmek istiyor. Böylece sanatın düşünceyi meşgul eden, rahatını kaçıran yönünü vurgulamaktadır. Özellikle 1970'li yıllardan bu yana heykel, artık ne geleneksel ne de modernist anlamıyla tanımlayabileceğimiz bir üretim çeşitliliği içindedir. Robert Smithson, Michael Heizer, Nancy Holt gibi sanatçılar heykel sanatının çeşitli sorunlarının göz önünde bulundurarak doğada ürettikleri yapitlarını 'çevre sanatı' diye adlandırılmışlardır. Bu sanatçıların, sanat malzemesi olarak galeri içine alınamayacak kadar büyük ya da satılamayacak bir nesne olan yeryüzünü kullanmalarının temel amacı, sanat nesnesinin metalaştırılmasından uzaklaşmaktı. 
Beuys 'sosyal heykel' terimini kullanmıștır. Beuys'un son çalışmalarında konferanslar, açık oturumlar etkili olmuştur. Onun derslerinde dünyàyı olumlu anlamda değiştirecek konular tartışılarak çözümler aranmış, girişimde bulunmak amacıyla simgesel anlamda 7.000 meşe fidanı dikilmiştir (Antmen,2008, 72).

Morris'in belirttiği gibi sanatçının tamamlayıp, sunduğu eserde süreç görünmez. Ancak eserin oluşum sürecide son hali kadar önemlidir. Parçaları eklemlendirmek, dönüştürmek, 1sı, hava gibi faktörler sonucu etkiler. Çevresel Sanat, New York’ta 1970'lerde Feminist görüşten de beslenmiştir. Bu hareketin içinde birçok kadın sanatçı da yer almıştır. Bu sanatçılar, doğada çalışırlar. Feminism/ Land Art'ın sanatçları arasında Cecile Abish, Âlice Adams, Âlice Aycock, Agnes Denes, Harriet Feigenbaum, Suzanne Haris, Nancy Holt, Mary Miss, Patsy Norvell, Jody Pinto, Patricia Johanson ve Athena Tacha yer alırlar. Bu sanatçılar, New York kökenli sanatçılardır. Kadın sanatçılar, bu yönelimde oldukça etkin bir rol oynamanın yanı sıra farklı üslup ve tarzları ile belirgin bir farklılık yaratmışlardır. 1970 lerde kurulan WACK: Art and the Feminist Revolutıon'n bir bölümünü teşkil eden Feminism/Land Art kadın sanatçı odaklıdır. Dış mekanda, alanda çalışan kadın heykeltıraşlar, Michael Heizer, Richard Long, Dennis Oppenheim ve Robert Smithson dan oluşan ilk Land Art jenerasyonundan sonra 1970'lerde aktifleşerek varlıklarını duyurmaya başlamışlardır . İlk kazmalar, tepeler, çukurlardan sonra ki Land Art ya da sonraki jenerasyon dönemi bu dönemden farklı bir anlayış ile kendini gösterir (Yaman, 2000,13).

Uzay ve Astronomi ile ilgili çalışmalar yapan Holt'un çalışmaları arasında Güneș Tünelleri, Dark Star Park, Sky Höyük, Güneş Web, Kutup Dairesi ve Çapraz Star yer almaktadır. ..Güneş, ay ve yıldızların hareketlerini izlemek, bunların günün faklı saatlerinde toprağa yeryüzüne bıraktığı izleri fotoğraflayarak, filme çekebilmek için tasarladığı Land Art Çalışmaları’ndan biri olan 'Güneș Tünelleri' toprağa gömülü beton borulardan oluşmaktadır. Üzerlerinde delikler vardır. Deliklerden içeri yansıyan güneş 1şıkları eser ve toprak üzerinde değişik görüntüler ve yansımalar oluşturmaktadır. 'Güneş Tünelleri' X figürasyonu şeklinde dört büyük beton daireden oluşmaktadır. Bu şekiller, yaz, kış, gün doğumu, gün batımı ile ilgili olarak farklı yansımalar sunarlar. Utah’da Büyük Havza Çölü’nde bulunan bu düzenleme Sanatçı 'Sky Höyük' adlı çalışmasıyla sadece sanat yapmaz alternatif enerji de üretir. Ayrıca tüm eserleri insanlar tarafından erişilebilir, ziyaret edilebilir bir özellik taşır. Bu çevresel düzenlemeleri görmek için müzelere gitmek gerekmez (http-1) (Görsel 1).

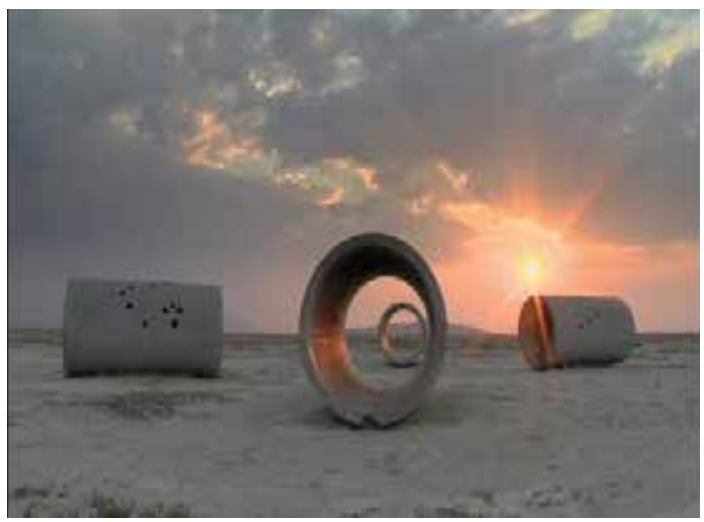

Görsel1. Nancy HOLT, Sun Tunnels, 1280x720, 19731976, Great Basin Desert, Utah

Eski bir benzin istasyonunu bir heykel parkına çeviren sanatçı aynı zamanda bir peyzaj tasarımcısıdır. Bu heykel parkındaki düzenlemesine 'Dark Star Park' adını vermiştir. Küreler, havuzlar, yaya yolları'ndan oluşan park'ta formlar ve çevre düzenlemesi yoğun, karmaşık ve materyalist şehir ortamı içerisinde tezat durmaktadır. Park, yanından geçenlere kısa bir süre de olsa büyük şehirden kaçma fırsatı vererek, oturulacak yerleri ve yürüyüş yolları ile izleyicinin algısını bir anda değiş̧irir (http-1). 


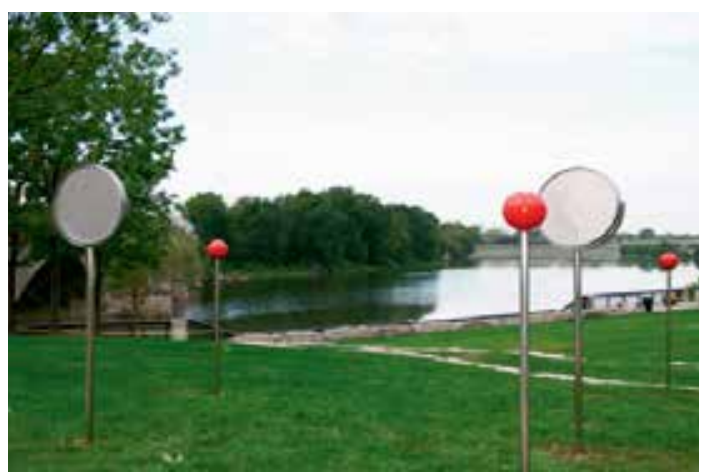

Görsel 2. Mary MISS, 'View of Mary MIss's long-term installatıon Flow: Can You see the River?,2011, tree red marker and two etched mirrors. Courtesy Indianapolis Museum of Art.

Konu ile ilgili olarak çalışan bir başka sanatçı, Mary Miss, nesneler, manzara, fiziksellik arasında görsel bir ilişki amaçlamıştır. Mimari, peyzaj tasarımı, bahçecilik kültürü üzerinde çalışmalar üretmiştir. Dünyanın çeşitli yerlerinde yapılan yürüyüşlerin fotoğraflarını çekmiştir. En çok 'su' unsuru ile ilgilenmiştir.1960'lardan itibaren peyzaj, mimari, alt yapı ve ekoloji uygulamaları yapan sanatçı, özellikle New York üzerinde çalışmış projeler üretmiştir. 1980'lerin başında 'Battery Park City South Cove' u dizayn ederken Hudson Nehri çoğu insan için erişilebilir değildir. O zamana kadar New Yorklular bir ada da yaşayan ancak nehre yaklaşamayan insanlardır. Mary Mıss insanlarla nehri yakınlaştırmıştır. Amacı nehir kokusunu insanlara hissettirmek, insanların ayaklarını ıslatmalarını sağlamaktır. Nehrin yanında ve adanın içinde bir rahatlama alanı yaratmıştır. Açık havada çalışırken manzara deneyiminin insanların yaşantısını olumlu yönde etkilemesi fikrinden hareket etmiştir. Battery Park’ta ahşap panellerle oluşturulan bir dizi geçici set tesis etmiştir. Toprak ve su arasında bir geçiş yapmak için suya kazıklar koymuştur. O parkın ortasında Özgürlük Anıtı gibi bir gözetleme kulesi yaratmıştır. Kendi başına bir heykel olan kule, 360 derecelik bir görünüm sunmaktadır. Mary Miss: 'İnsanlar galerilerde hiçbir şeye dokunamazlar. Ama ben daha ziyade insanların bunları kullanmaları ile ilgileniyorum' der. Parkın içinde küçük-büyük köprüler, geçitler vardır. Bunların hepsi su ile iç içedirler. Nehir üzerindeki

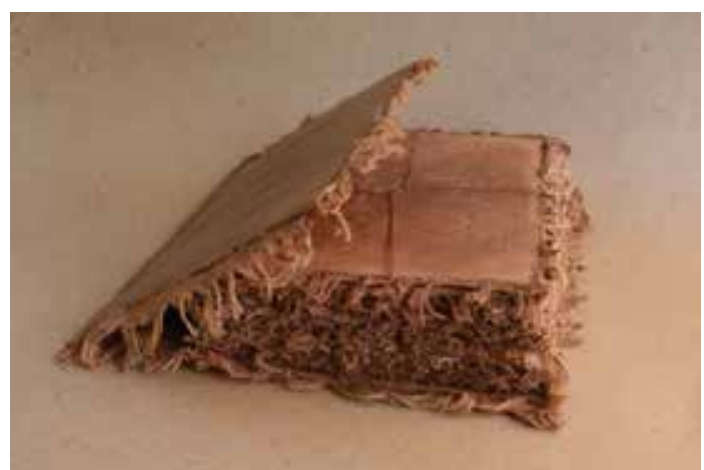

Görsel 3. Mıchelle STUART, 'San Juan Ermita Chiquimula', 1978, Hamptons Art Hub.

kemerler ve iç bükey güverte insanları karadan uzaklaştırır nehre yaklaştırır. Parkın içinde aynı zamanda yeşil alanlar, oturma ve aydınlatma elemanları da vardır (http-2).

Mary Mıss, diğer kamu projelerinde tabelalar, aynalar, yazılı metinler kullanır. Şehri ilgilendiren sorunları çözmeye yönelik kara, hava, su, atıklar, gıda temini, enerji ile ilgili tüm sorunlara plastik anlamda çözümler bularak ayna, tabela ve yazılı metinler gibi elemanları birer estetik öğe olarak sokaklara, caddelere, yollara, parklara yerleştirir. Eserleri ile kamuoyunun ilgisini çevremize çekmenin yeni yollarını arayan sanatçılardan biridir (http-2).

Michelle Stuart, 1960'lardan bu yana toprak üzerine tasarımlar, çizimler projeler yapan bir sanatçıdır. Çalışmalarını gerçekleştirirken tarih, astronomi, botanik, arkeoloji, antropoloji, haritacılık, biyoloji ve edebiyattan faydalanır. Çalışmalarında balmumu, çiçek, tohum, kül, fosil ve bitkilerin kullanımına öncülük edenlerdendir (http-3) (Görsel 3).

Alice Aycock, Kamuya açık alanda büyük boyutlu neredeyse yarı mimari olarak nitelendirebileceğimiz çalışmaları ile izleyici de psikolojik olarak etkilemek istemiştir. Sanatçının çalışmaları paradigmalar, sibernetik, fenomenoloji, fizik, post-yapısalcılık, psikanaliz ve bilgisayar programlarına dayanır. Mimari ve heykel sayabileceğimiz büyük boyutlu çalışmaları hem duygusal hem de zihinsel bir duyarlılık taşır. 


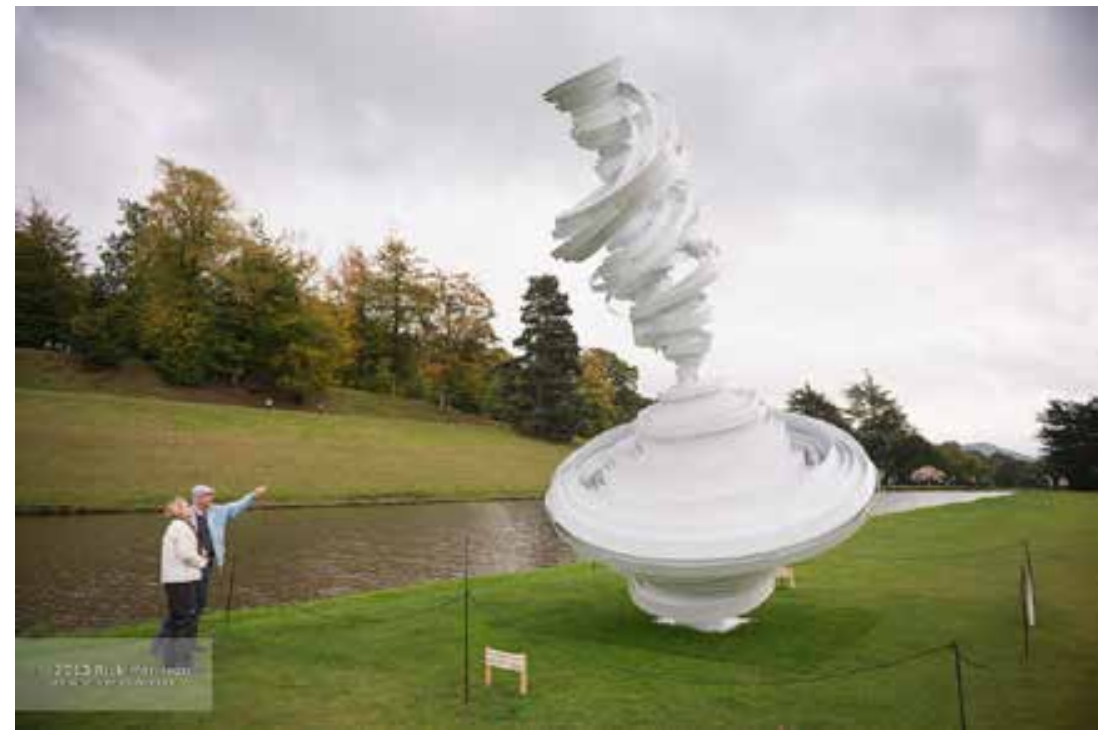

Aycock, izolasyon, yabancilaşma, oryantasyon bozukluğu, sıkışmışlık ve korku’nun varoluşsal ve fiziksel pozisyonlarını keşfederek onları üç boyutlu yapılara dönüştürür (http-4) (Görsel 4).

Alice Aycock'un New York, Park Avenue'da yaptığ 1 soyut, alüminyum boyal, fiberglas bir dizi çalışmasına 'Paper Chase' adını vermiştir. Doğa olaylarından özellikle dalga, rüzgâr, enerji girdaplarından ilham alan bu çalışmaları için Eric Rolfsen 'Kamu sanatı büyük olmalıdır' derken 'çiçek demetini andıran kâğıt güllere beziyor' diye eleştirmiştir Irene Stolzerder. Bilim kurgu öğelerinde de ilham alan sanatçının çalışmaları anıtsal olmalarının yanı sıra eğrilen, bükülen formlardır. Çoğu zaman birbiri üzerine yıkılan bu formlar, rastgele ve gelişigüzel tasarlanmış gibidirler.

\section{SONUC̣}

1970'lerden 80'lere uzanan süreçte, nesneye bakış açısının çeşitlenmesi her bir sanat disiplininin kendi tanımlı alanına ait olandan sıyrılmasına, yeni bir dil oluşturma çabası içinde sınırlarının genişletilmesine olanak sağlar. Özellikle heykel alanında, asamblaj çalışmalarının büyük çaplı enstalâsyonlara oradan da arazi uygulamalarına kayması, hazır nesne, popüler tüketim nesnesi, kullanımının yaygınlaşması; nesne heykeller, nesneleşen mekânlar-bedenler gibi tanımların yaygınlaşmasını sağlar. 1960'lardan itibaren sanatta hızlı ve köktenci bir değişime tanık oluyoruz. Bu değişim nesne’nin dış görünüşünden ziyade zihinsel boyutunda nesne-kavram sorununu tartışmıştır. Kendine ait sorunları tartışırken, asli görevi kavram üretmek olan felsefenin işlevini de üstlenmiştir. Beykal bu konu ile ilgili olarak 'Yeni rakipler, felsefenin kavram üretmek olan asli görevine talip olmuşlardır' (Beykal, 1996,33) der. Sanattaki yaratma terimi, felsefenin kavram üretme görevine denk düşüyor gibidir. Ancak kavramlar nesnesiz şeylerdir. Sanatı felsefeden ayıran, uygulamayı kuramla birleştirmesidir. Bu nedenle sanat kendi kavramını ortaya koyarken nesnesini de gösterir. Ortaya konan nesne kavrama, kavram da nesneye gönderme de bulunur. Kavramsal sanat her nesnenin anlattığı bir şey olduğuna ve içinde bir alt metin taşıdığına inanır. AkayZeytinoğlu’nun söylemlerine göre; '...disiplinlerarası dediğimiz şey, sanatçının kişisel ve bir kereye mahsus kararı kadar sanat sayılabilir ancak. Demek ki; bundan böyle bir yapıt ya da eylemin, nereden nereye kadar sanat, nereden nereye kadar dilbilim, nereden nereye kadar sosyoloji, nereden nereye kadar tarih, nereden nereye kadar siyaset, istatistik, çevrebilim, muhasebe, tıp, gen mühendisliği, astronomi v.s olduğu üzerine izleyicinin mutlak bir ön bilgilendirmesi doğmaktadır' (Akay- Zeytinoğlu, 1998, 112). 


\section{KAYNAKLAR}

- Antmen, A. (2008) 'Post Modern Dönemde Heykel Ve Nesneler', 'Sanatçılardan Yazılar Ve Açıklamalarla:20.Yüzyıl Batı Sanatında Akımlar. İstanbul: Sel Yay.

- $\quad$ Akay, A. - Zeytinoğlu, E.(1998). Kavramın Sinırlarında, Bağlam Yayınları.

- $\quad$ Genette, G. (1992). Sanatı Tanımlamak, Estetik Ve Poetika İçinde, Seuil

- Gelburd, G.(2009). 'Veiled Art And Politics'

- Goodman, N. (1992). Manieres de faire des Mondes, Jacqueline Chambon, Nimes

- Heiddegger, M. (2011) Sanat Eserinin Kökeni, Ankara,2.Basım

- Judith, C. (2007) 'Post-Pop Objects', Sculpture Today.London:Phaidon Press

- $\quad$ Krauss, R. E. (1983). 'Sculpture In The Expanded Field'Hal Foster.The Anti-Aesthetic:essays on post modern culture.s.l.:Port Townsend, Wash.:Bay Press

- $\quad$ Lenoir, B.(2003). Sanat Yapıtı, Çev. Aykut Derman, Yapı Kredi Yayınları, İstanbul

- Sarup, M. (1993). Post-Yapısalcılık ve Postmodernizm,Çev. A.Baki Güçlü,Bilim ve Sanat Yay./ARK: Ankara

- Yasa, Y, Z.(2000). “Modernizmin Alternatifleri:1970’lerde Sanat”, Plastik Sanatlar Dergisi Ark, sayı6-7,Çağdaş Heykeltıraşlar Derneği yay: Ankara

\section{Internet Kaynakları}

- http-1: http://www.artsy.net/article/artsy-editorial-story-sun-tunnels-nancy-holts-land-art-masterpiece (Erişim: 02.08.2019)

- http-2:http://www.artinamericamagazine.com/news-features/magazines/mary-miss (Erişim:11.09.2019).

- http-3: http://www.michellestuartstudio.com/AboutArtist.htm (Erişim: 09.12.2018)

- http-4: http://mitpress.mit.edu/boks/alice-aycock/?cr=reset (Erişim: 01.12.2018)

\section{Görsel Kaynaklar}

- https://www.google.com/search?q= nancy+holt+sun+tunnels. (Erişim: 07.03.2019)

- $\quad h t t p s: / / w w w . g o o g l e . c o m / s a e r c h ? q=a l i c e+a y k o k .($ Erişim: 09.03.2019)

- $\quad h t t p: / / w w w . n y t i m e s . c o m / 2014 / 03 / 12 / a r t s / d e s i g n / a l i c e-a y c o c k s$ (Erişim: 07.11.2018)

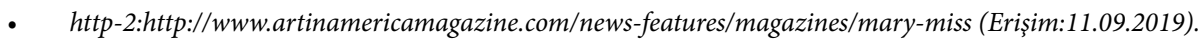

- http-3: http://www.michellestuartstudio.com/AboutArtist.htm (Erişim: 09.12.2018) 